\title{
O QUE FAZ VOCÊ FELIZ? REFLEXÕES SOBRE A PSICOLOGIA NA SOCIEDADE DE CONSUMO
}

\author{
$*$ \\ Marcio Acselrad \\ Universidade de Fortaleza - UNIFOR - Brasil \\ Josefa Crysleide Rodrigues Lopes \\ Universidade de Fortaleza - UNIFOR - Brasil
}

\section{Resumo}

O presente trabalho objetiva identificar como se dá a busca pela felicidade através do consumo e quais são as implicações subjetivas desse processo através da investigação de como a psicologia define o que é a felicidade e como esta se relaciona com as atuais práticas de consumo. Para tanto foi feita uma revisão bibliográfica sobre o tema juntamente com a realização de entrevistas com psicólogos e um grupo focal com estudantes universitários. A partir das informações obtidas pode-se fazer uma explanação sobre a definição de felicidade e como o consumo é a ela atrelado. Assim, pudemos compreender que a felicidade é fruto de muitas fontes e vivências e que o consumo tem sido um meio privilegiado de se conseguir prazer e bem-estar.

Palavras-chave: Felicidade; Consumo; Psicologia; Pós-modernidade.

\section{Considerações iniciais}

Considerando o aparato tecnológico, o avanço científico, a rapidez da informação e da comunicação numa sociedade do imediatismo que é constantemente bombardeada por novidades do mercado, onde o supérfluo luta para se tornar necessário, vivemos um momento paradoxal, onde se por um lado clamamos por fortes identificações com vários objetos e pessoas, para as quais transferimos afeto e energia pulsional, por outro vivemos uma constante necessidade de diferenciação, de distinção e singularidade. Neste sentido acreditamos ser fundamental a colocação da seguinte questão: o que é ser feliz?

Por meio de uma análise de nossa história recente, percebe-se uma clara relação estabelecida entre felicidade e consumo, relação esta que não se apresentava em eras anteriores como a antiguidade e a Idade Média, em que o cuidado de si, a busca da virtude e da excelência ou a fé ocupavam o centro das atenções. Dessa forma, constatamos que a felicidade é um conceito muito relativo, uma vez que sua definição é dada de acordo com o período histórico, o povo e a cultura que se tem por referencial. 
O consumo é bastante incentivado nas sociedades contemporâneas. As pessoas consumem e descartam cada vez mais e numa velocidade sempre maior. Tal consumo não se restringe apenas a produtos e serviços, mas também a modos e estilos de vida. Ideias são vendidas como forma de vida satisfatória e modelos ideais a serem seguidos e as pessoas que porventura não se enquadram nesses padrões ficam a margem da sociedade por não compor o que o mercado apresenta como belo e bom (LIPOVETSKY, 2007).

Este trabalho se iniciou a partir da inquietação de como se dá a busca da felicidade através do consumo e quais suas implicações subjetivas. Tal questão tornou intuito desta pesquisa identificar como a psicologia define o que é a felicidade e como esta se relaciona com a prática do consumo, juntamente com a investigação sobre como esse fenômeno é percebido pelos sujeitos contemporâneos.

A relevância deste estudo se justifica pela possibilidade de tornar mais compreensível o fenômeno do consumo exacerbado como caminho de conquista da felicidade, o qual é estruturado nas vivencias dos sujeitos contemporâneos, como também no fornecimento de subsídios para uma reflexão sobre por quais vieses estão enveredando os anseios subjetivos da atual sociedade e a percepção concomitante da lógica da sociedade contemporânea com as repercussões psicológicas provenientes da relação sujeito-objeto.

Para realizar tal investigação faz-se importante primeiramente definir o que se entende por felicidade como também apontar alguns esclarecimentos acerca da dinâmica da atual sociedade para que dessa forma possa ser delineada a relação entre felicidade e consumo.

\section{O que é a felicidade?}

Notoriamente a felicidade é um tema que se faz bastante presente em diversos contextos da vida cotidiana. As atitudes e vivencias em geral almejam um objetivo. E a felicidade tem se apresentado constantemente como o objeto dessa busca. Mas afinal, o que é a felicidade?

Essa é uma questão que há muito tempo tem sido colocada e que muitos tentaram definir. Para tanto, faz-se necessário uma investigação de como a felicidade é pensada de época para época, uma vez que cada período possui suas características, ideologias, valores, crenças e cultura própria. Assim, pode-se pensar a felicidade como um conceito dado ao relativismo e em última instância a um hiper-relativismo, uma vez que cada um percebe e busca a felicidade a seu modo. 
De acordo com Epicuro (1973), em “Carta a Meneceu”, a felicidade ou a finalidade da vida humana é o prazer. Ele coloca que todas as ações humanas devem ter em vista um bem ultimo, qual seja o prazer. Segundo este mesmo autor, desde o nascimento as pessoas buscam o prazer e evitam a dor. Para melhor entender a ideia de felicidade para Epicuro é importante destacar o seu conceito de prazer:

\footnotetext{
"Não nos referimos aos prazeres dos intemperantes (...) ou aos que ignoram nosso pensamento, ou não concordam com ele, ou o interpretam erroneamente, mas ao prazer que é a ausência de sofrimentos físicos e de perturbações da alma. Não são, pois, bebidas nem banquetes contínuos, nem a posse de mulheres e rapazes, nem o sabor de peixe e iguarias de uma festa farta que tornam doce uma vida, mas um exame cuidadoso que investigue as causas de toda a escolha e de toda a rejeição e que remova as opiniões falsas em virtude das quais uma imensa perturbação toma conta dos espíritos. (...).” (EPICURO, 1973, p. 4).
}

Portanto, prazer neste contexto não se refere à busca hedonista de realização, mas antes a uma visão de mundo que trate o desejo com moderação e as ações sem exagero, o que leva o homem a um estado de estabilidade. Assim, a felicidade se refere ao bem do corpo e da alma que, uma vez alcançados, não tornam necessário ao homem buscar mais nada que o satisfaça, uma vez que, na presença do prazer, a satisfação é plena. E só há necessidade se o prazer estiver ausente (EPICURO, 1973).

Ainda segundo Epicuro (1973) tanto o prazer como a dor da alma são maiores do que os do corpo. Pois o prazer da alma supera a dor do corpo e, a dor da alma sufoca o prazer do corpo, alem de se remeter a sofrimentos presente, passado e futuro. Ele ainda afirma que existem dores que podem levar a maiores prazeres e prazeres que podem causar dores maiores, por isso é importante fazer escolhas e rejeições usando a razão, a qual é capaz de avaliar que prazeres momentâneos não compensam pelo sofrimento futuro que podem causar.

Aristóteles, por sua vez, tratou da felicidade como sendo uma "sorte de especulação e de ação" (1990, p.161) que acontece na intimidade da vida. Porem, a ideia aristotélica de felicidade relaciona-se ao coletivo e é considerada como responsabilidade do Estado. Pois, o estabelecimento da felicidade advém da perfeição da ação e a perfeição está, neste período, para o Estado (ARISTÓTELES, 1990), ou seja, o Estado era responsável pelo estabelecimento de uma polis onde os homens como cidadãos de ideais políticos pudessem ser felizes.

Com isso, o pensamento de Aristóteles se aproxima ao de Epicuro, por considerar que “a felicidade não consiste em divertimentos... que feliz é a vida conforme a virtude" (1990, p.153). Ele coloca a felicidade como algo que se conquista em longo prazo por meio da maturidade, da longevidade. $\mathrm{E}$ isso se dá porque nada de imperfeito existe na felicidade. Esta Barbarói, Santa Cruz do Sul, n.46, p.<233-248>,jan./jun. 2016 
é outra característica comum à teoria de Epicuro, o qual coloca a felicidade como a ausência de toda perturbação. Porem há discordância entre eles no fato de Epicuro (1973) afirmar que a vida política causa perturbações e o homem deve se afastar destas.

Mais tarde, Freud (1930), em o "Mal-estar na civilização", afirma que a questão sobre a finalidade da vida humana é algo que perpassa a historia da humanidade desde o inicio da civilização. Ele defende que as respostas a essa questão até então encontradas seriam insatisfatória. O que tem revelado a conduta dos homens com relação a essa finalidade da vida nada mais é do que a busca pela felicidade (FREUD, 1930).

De acordo com a teoria freudiana do principio do prazer e principio da realidade, a felicidade ou a "finalidade da vida" que é alcançada por meio do principio do prazer, o qual se refere ao desejo de gratificação imediata, leva o individuo a buscar o prazer e evitar a dor (FREUD, 1930). Dessa forma, seria a felicidade uma espécie de satisfação repentina que ocorre em momentos passageiros deixando ao individuo algo da ordem do bem-estar. "Logo, nossas possibilidades de felicidade são restringidas por nossa constituição" (FREUD, 1930, p.31). Pois, ainda segundo Freud (1930), é mais fácil ao homem ter acesso à dor e ao sofrimento, os quais ameaçam constantemente suas vivencias através do corpo, do mundo e das próprias relações humanas.

Portanto, o que se percebe inicialmente do discurso de Freud sobre a felicidade é que se trata de uma conquista vinda de elementos externos ao individuo. Contrariamente a isso, Csikszentmihalyi (2005) diz que a felicidade não depende de acontecimentos externos, mas sim da forma como tais acontecimentos são interpretados por cada um. Para a autora, o mais próximo que se pode chegar da felicidade ocorre pela capacidade do individuo controlar suas experiências internas e isso é o que determina a qualidade de vida das pessoas. Assim, a felicidade se trata de "uma condição vital que cada pessoa deve preparar, cultivar e defender individualmente" (CSIKSZENTMIHALYI, 2005, p.13).

Segundo Giannetti (2002), propor uma definição de felicidade é uma tarefa pretensiosa, pois alem de está sujeito a objeções a "felicidade não é uma coisa absoluta. Como as noções de quente e frio, ela só se define pelo contraste com seu oposto" (p. 155). Porem, se tratando da felicidade como uma vivencia global, ele coloca que quem é feliz "deve ter encontrado inúmeras coisas que o deixaram feliz e, naturalmente, deve ter desfrutado de muitos momentos felizes" (p. 36).

Giannetti (2002) também afirma que a felicidade sempre foi e continua sendo considerada a grande finalidade da vida e que em nome dela "se justificam escolhas na vida pública e privada" (p. 68). Contudo, citando a ética kantiana, a qual desconsidera a felicidade Barbarói, Santa Cruz do Sul, n.46, p.<233-248>,jan./jun. 2016 
como o bem supremo, ele apresenta a convergência da autonomia - valor central da vida ética - e o bem-estar como componente da felicidade.

\footnotetext{
(...) Aos olhos de Kant, portanto, a felicidade não se reduzia ao cálculo hedonista ou à otimização do saldo de afetos positivos (prazer) sobre afetos negativos (desprazer). Ela seria uma espécie de bônus ou prenda involuntária coroando uma boa-fé inquebrantável e a consciência do dever cumprido (GIANNETTI, 2002, p. 28-29).
}

Neste sentido, percebe-se que a ideia de felicidade está diretamente ligada a noção de bem-estar. O bem-estar, por sua vez, pode ocorrer tanto objetivamente como subjetivamente. Isto vai depender das interpretações que o individuo dá a situação, ao meio e as transformações ocorridas (GIANNETTI, 2002).

\section{Sociedade moderna, pós-moderna e a felicidade}

De acordo com Giannetti (2002, p.21) "o grande divisor de águas no tocante à evolução da noção de progresso civilizatório e do seu impacto sobre a felicidade humana foi o iluminismo europeu do século XVIII", a partir de então se inicia a era da razão, se propaga o pensamento de que há uma proporcionalidade equilibrada de progresso civilizatório e felicidade.

Com isso, é importante se fazer uma breve exposição dos períodos históricos conhecidos por modernidade e pós-modernidade, para uma melhor compreensão desse fato, como também de como o conceito de felicidade foi se modificando até se estabelecer no paradoxo conceituado por Lipovetsky.

Primeiramente situa-se a era moderna ou modernidade, a qual se refere ao período que passou a ser denominado de cultura de massa. Quanto à definição de período cronológico há divergência entre os autores. A modernidade foi divida, por Marshall Berman (1980), em três fases. A primeira fase diz respeito a um tipo de previa do processo das grandes transformações que estavam se iniciando na sociedade, mas esta não teve muita consciência desses fatos. A segunda equivale às transformações estruturais advindas da Revolução Francesa que idealizavam conceitos de democracia, igualdade, individualidade, universalidade e autonomia. Por fim, na terceira fase, as coisas se iniciam num processo de complexidade, onde o projeto moderno apresenta problemas de diversas ordens, tais como reivindicações políticas pelos menos favorecidos, lutas de classes, crise da individualidade subjetiva, dentre outros. 
Esse terceiro período é marcado por sua complexidade, uma vez que a modernidade foi o motor gerador de uma reviravolta dos antigos conceitos legitimados pela igreja e pelo Estado. Uma abstenção do passado e da tradição. Como afirma Lipovetsky $(2005$, p.61) "entre 1890 e 1930 a modernidade assume toda a sua amplitude".

A partir desse estabelecimento, pela modernidade, de rompimento com a continuidade do passado, a liberdade passou a ser o novo conceito da sociedade. Essa liberdade vai contra as reformulações impostas pela tradição, "ela se manifesta por um processo hiperbólico de negação das regras heterônomas e correlativamente, por uma criação autônoma que decreta suas próprias leis" (LIPOVETSKY, 2005, p.73). Por essa ruptura com a tradição e as convenções se adota um novo modelo de vida onde é preciso criar ou recriar suas próprias referências, considerando que essa mesma liberdade está atrelada ao princípio de igualdade, sendo direito de todas as pessoas prosseguirem nesse mesmo processo.

Sérgio Paulo Rouanet (1998) afirma que a modernidade se sustenta sobre três pilares, quais sejam: a universalidade, a individualidade e a autonomia.

Sendo a universalidade o termo utilizado para explicar a modernidade como um projeto que envolve todas as pessoas e derruba barreiras como etnia, cultura e nacionalidade. Através do universalismo se apresentava o projeto civilizatório da modernidade, pelo qual todos teriam a possibilidade de emancipação e consequentemente, a felicidade, pois já não haveria conflito entre os homens. Todos passam a ter acesso ao que o mercado oferece.

Por conseguinte, a individualidade é colocada como uma descaracterização das pessoas como integrantes de uma coletividade e aprovada como seres efetivos de particularidades e necessidades além às da coletividade. Nesse contexto, a ideia de individualização pode, por sua vez, ser desencadeadora de um grande leque de opções de características e personalidades para que o sujeito faça suas escolhas como quem busca uma mercadoria na prateleira de um supermercado.

Por sua vez, o termo autonomia se remete à quebra das amarras da humanidade à religião e às questões ideológicas. A autonomia se estabeleceu para dentro de cada individuo ao invés de uma ordem de cima para baixo. Nessa compreensão de autonomia, a felicidade é meta final dos comportamentos e escolhas do individuo em todas as esferas da sua vida (GIANNETTI, 2002). E é também o meio pelo qual o sujeito pode afirmar sua individualidade.

A partir dessas considerações pode-se apontar a modernidade como sendo um período marcado por mudanças, rupturas, rapidez e deslocamento. Tudo isso contribui para caracterizar a sociedade moderna como uma pluralidade destituída de qualquer centro de Barbarói, Santa Cruz do Sul, n.46, p.<233-248>,jan./jun. 2016 
articulação ou organização (HALL, 2000). A efetivação de tais aspectos encaminha a sociedade para um próximo estagio de definição, o qual se denomina pós-modernidade.

O pós-moderno, por sua vez, é um período histórico marcado por mudanças nas ciências, nas artes, nas sociedades e gradativamente foi se definindo, dentre outros, por meio da arquitetura, da computação, da filosofia, da música, do cinema e principalmente da tecnologia (SANTOS, 2000).

Caracterizado, fundamentalmente, por um cotidiano perpassado pela "tecnologia eletrônica de massa e individual, visando a sua saturação com informações, diversões e serviços" (SANTOS, 2000, p. 9), a pós-modernidade leva os indivíduos a lidarem mais com os signos ao invés de coisas, alem de fomentar o consumo personalizado que atrela sedução e moral hedonista na conquista do individuo (SANTOS, 2000).

O pós-modernismo ameaça encarnar hoje estilos de vida e de filosofia nos quais viceja uma ideia tida como arqui-sinistra: o niilismo, o nada, o vazio, a ausência de valores e de sentimentos para a vida. (...) O homem pós-moderno (...) se entrega ao presente e ao prazer, ao consumo e ao individualismo (SANTOS, 2000, p. 10-11).

Segundo Baudrillard (1995), tudo isso ocorre porque as relações de consumo não se dão mais pela utilidade do objeto em si e, sim ao conjunto dos objetos e a significação dessa totalidade.

Enquanto a modernidade se apoiou em ideais de liberdade, Bauman (1998) coloca que na pós-modernidade a liberdade deu lugar a segurança. Dessa forma, os "mal-estares" existentes na atualidade advêm da ordem que em nome da segurança sacrifica a liberdade individual de buscar o prazer (BAUMAN, 1998).

Assim sendo, fica claro a mudança de valores e significados da sociedade moderna para a pós-moderna. A primeira manteve uma relação de consumo voltada para a funcionalidade e durabilidade dos bens, na qual se buscava suprir as necessidades para ser feliz. Já no pós-modernismo se percebe que o importante é, principalmente, a estética, onde o consumo personalizado proporciona prazer e felicidade pelo bem-estar momentâneo.

Este fato do consumo passar a ser motivado pelo conforto e formas de vida mais hedonista, segundo Lipovetsky (2007), estimulou a noção de felicidade privada por meio do lazer e menos submetida ao julgamento do outro.

Agora, a busca das felicidades privadas, a otimização dos nossos recursos corporais e relacionais, a saúde ilimitada, a conquista de espaços-tempos personalizados é que servem de base a dinâmica consumista: a era ostentatória dos objetos foi suplantada pelo reino da hipermercadoria desconflitada e pós-conformista. (LIPOVETSKY, 2007, p. 43). 
A partir do que se consome e como é consumido, o sujeito tem a possibilidade de mostrar-se a sua maneira, singularmente. O consumo instigado pelo desejo não representa mais um atrativo ao sujeito pós-moderno, o que agora é valido é a dimensão imaginaria que o produto pode fornecer. No sentido de que o individuo possa adquirir por meio do produto um estilo de vida (LIPOVETSKY, 2007).

O hiperconsumidor, como denomina Lipovetsky (2007), busca no consumo mais do que coisas e símbolos, ele consome o que ainda não se materializou. O foco da aquisição de produtos está no desencadeamento de emoções, afetos. Isso gera uma cultura de consumismo pela satisfação dos prazeres imediatos, do lazer, da felicidade individual, do gozo aqui e agora numa vida para si mesmo.

Essa promessa de felicidade apresentada como bem-estar instantâneo abrange duas dimensões, que são definidas por Giannetti (2002):

\begin{abstract}
Existe uma dimensão objetiva, passível de ser publicamente apurada, observada e medida de fora, e que se reflete nas condições de vida registradas por indicadores numéricos de nutrição, saúde, moradia, uso do tempo, renda per capita, desigualdade, criminalidade, poluição e assim por diante; e há uma dimensão subjetiva, que é a experiência interna do indivíduo, ou seja, tudo aquilo que se passa em sua mente de forma espontânea enquanto ele vai vivendo e agindo no decorrer dos dias e que volta e meia ocupa a sua atenção consciente nos momentos em que ele se dá conta do que está sentindo e pensando ou reflete sobre a vida que tem levado (p. 61).
\end{abstract}

Contudo, Giannetti (2002), também afirma que é importante considerar que as pessoas, os grupos, possuem diversificados valores, apresentam diferentes preferências, envolvem-se em varias relações pessoais e cada um incorpora um sonho, que não necessariamente implica a felicidade.

Nestes aspectos, Baudrillard (1995), trás a compreensão de que a felicidade remete a uma vivencia "controlada, (...) difundida na indistinção das coisas e das relações sociais" (p. 21). Em seu livro "A Sociedade de Consumo" ele faz uma analogia da construção de um simulacro pelos indígenas da Melanésia no intuito de que os aviões pousassem em seu território com a forma como os indivíduos pós-modernos procuram a felicidade, como se essa fosse alcançada milagrosamente por meio do "sistema de interpretação" que compõe a via cotidiana (BAUDRILLARD, 1995). 


\section{Metodologia}

O presente artigo trata-se do resultado da realização de uma pesquisa qualitativa, para a qual foi feita uma revisão bibliográfica a partir das considerações teóricas de alguns autores com Lipovetsky (2007), Giannetti (2002), Aristóteles (1990), Baudrillard (1995), Bauman (1998) e Rouanet (1993), acerca do conceito de felicidade, no qual se discute sua formação, sua relação e suas formas preponderantes na sociedade de consumo contemporânea, como também suas implicações psicossociais para o sujeito.

Para tanto o estudo seguiu os padrões do método histórico de pesquisa, que, segundo Marconi e Pressotto (1998), consiste em:

Investigar eventos do passado, a fim de compreender os modos de vida do presente, que só podem ser explicados a partir da reconstrução da cultura e da observação das mudanças ocorridas ao longo do tempo (apud MICHALISZYN e TOMASINI, 2011, p. 50).

Além disso, dado o teor pratico do estudo, foi necessária a execução de pesquisa empírica com a utilização da entrevista dirigida e do grupo focal como ferramentas de investigação. Nesse aspecto, o trabalho foi inspirado no método comparativo ou etnológico, o qual "permite verificar diferenças e semelhanças apresentadas pelo material coletado. Compara padrões, costumes, estilos de vida, culturas (...) a fim de obter melhor compreensão dos grupos sociais pesquisados" (MARCONI e PRESSOTTO, 1998 apud MICHALISZYN e TOMASINI, 2011, p. 50).

As entrevistas foram realizadas com três psicólogos atuantes no campo acadêmico que têm suas práticas norteadas pelas seguintes abordagens psicológicas: a psicanalítica, a análise do comportamento e o psicodrama. E o grupo focal aconteceu com um grupo de seis estudantes universitários dos cursos de psicologia e áudio visual e um professor de filosofia, totalizando um grupo de sete pessoas, ativas no âmbito acadêmico e de ambos os sexos.

\section{Análise dos dados}

A partir das informações obtidas por meio das entrevistas realizadas pode-se fazer uma explanação sobre a definição de felicidade e como o consumo é a ela atrelado estabelecendo um paralelo entre as considerações propostas pelas abordagens psicológicas. 
Sobre a concepção de felicidade percebeu-se a predominância da ideia de "relações" entre as explicações dadas pelas três abordagens psicológicas, apesar de cada uma apresentar suas explicações com sua linguagem própria e diferentes fatores determinantes.

O psicodrama trás a ideia de felicidade literalmente como uma relação que se dá do individuo com o próprio individuo e com o outro. Segundo o entrevistado, baseado na teoria de Moreno, a felicidade é algo que se define na noção de "encontro". Este, por sua vez, possui um sentido interpessoal, ocorre nas relações interpessoais. Tais relações se referem não somente ao âmbito coletivo, mas também ao que se entende por individual, pois o individual é construído da coletividade. Então, a noção de felicidade como algo que depende só do próprio individuo também parte das relações, mesmo que sejam relações com coisas. Portanto, a felicidade é sentida e encontrada nas relações interpessoais.

Na compreensão da análise do comportamento a felicidade é um estado emocional, como qualquer outro, culturalmente estabelecido e que é decorrente de um determinado evento ambiental, tal seja a apresentação de um reforçador. Em outras palavras, trata-se também de uma relação, do individuo com o meio. O diferencial dessa concepção é que ela não considera a felicidade como a causa de algum comportamento. Mas, sim como o resultado da interação entre organismo e ambiente numa relação de reforço.

Já para a psicanálise freudiana a felicidade está atrelada a definição de pulsões. Todas as pessoas são governadas pelas pulsões e instintos. As pulsões enfrentam o obstáculo das repressões sexuais na busca de satisfação, ou seja, para se viver em civilização o homem precisa recalcar suas pulsões. Dessa forma não há completude, logo também não se alcança a felicidade. Portanto, a felicidade refere-se à realização do desejo e esta só ocorrerá com a sublimação das pulsões. Por essa vertente pode-se então dizer que a felicidade é a relação do desejo inconsciente com as possibilidades reais conscientes.

Com relação a como ocorre à busca pela felicidade atualmente e o que representa a felicidade para os sujeitos contemporâneos, os relatos se voltaram para a explicação da mesma com um fenômeno continuo na vida dos indivíduos.

Pela concepção psicodramática a busca pela felicidade é um processo. Entendendo a felicidade como uma construção e que tal construção se dá pelas relações pode-se afirmar que não existe felicidade plena e sim momentos de felicidade, por isso sua busca é um movimento em constante construção. A ideia de felicidade plena é algo estranho ao homem. A felicidade "por um tempo foi associada ao morto, o sujeito morre vai para o paraíso e passa a ser constantemente feliz. Ser sempre feliz parece ser uma coisa monótona, parece um padrão de uma maquina”. Dessa concepção, a busca da felicidade pressupõe uma construção, na qual o Barbarói, Santa Cruz do Sul, n.46, p.<233-248>,jan./jun. 2016 
sujeito precisa ativamente busca-la ate encontrar e novamente realizar todo o processo. Porem, não como uma repetição de forma circular, mas como um processo constante não duradouro. Momentos de felicidade constituídos pelo encontro, onde se estar sempre desenvolvendo novas determinações e buscando-as.

Com isso, a felicidade representa um meio do individuo melhor se conhecer. "Quando o sujeito está feliz há uma vivacidade em todo o corpo. Há uma manifestação corporal da felicidade que acarreta numa abertura para o novo, para o outro".

De acordo com a vertente psicanalítica atualmente vivi-se um período além do Édipo, no qual o individuo não está mais atrelado ao desejo. "A subjetividade contemporânea passa pelo corpo, pela ação e pelos sentimentos e não mais pela razão e pensamentos. Assim, a busca pela felicidade está diretamente ligada ao gozo dos objetos”. Por isso, como a felicidade ocorre por via do simbólico, hoje ela é tão difícil de ser alcançada. Não há mais a vivencia do simbólico. E como a pulsão é eternamente insatisfeita, o individuo está sempre em busca da tal felicidade havendo uma tendência a se achar que ela vem do gozo dos objetos.

Segundo a concepção comportamental, a busca pela felicidade trata-se de um comportamento que como todos os comportamentos segue a lei da tríplice contingencia (estímulo-resposta-consequência), “o processo é o mesmo não há variabilidade, o que muda em cada comportamento é o estimulo reforçador". No caso dos comportamentos emitidos no intuito de buscar como resultado a resposta emocional de felicidade o que vai sofrer variabilidade, em virtude do contexto histórico, é o estimulo que ocupa a função de reforçador na relação entre organismo e ambiente.

Ao serem indagados sobre como o ato de consumir pode ser ou estar relacionado à busca da felicidade, os entrevistados relataram sobre como tal fenômeno se estabeleceu mostrando a funcionalidade que esse comportamento possui.

De acordo com o psicólogo embasado pelo psicodrama, a felicidade pode ser equiparada a ideia de espontaneidade - presente na teoria de Moreno - a qual se refere à resposta ao novo que o sujeito apresenta quando está feliz. O consumo, por sua vez, poderia representar o caminho para se alcançar essa abertura ao novo, porém o que se percebe é o contrario. Pois a espontaneidade pressupõe a construção de algo e a aquisição de coisas no ato de consumir não envolve o processo construtor, compram-se os objetos prontos. O algo que já está pronto para ser utilizado é denominado por Moreno de conserva cultural. Esta é importante para que se possa conhecer o que foi construído por outras pessoas. Mas o que 
poderá efetivamente gerar felicidade é o algo ou a vivencia que o próprio sujeito tenha criado, tenha sido ativo em todo o processo construtor.

Segundo o analista do comportamento o ato de consumir bens materiais é um comportamento que foi selecionado pelo terceiro nível de seleção, o cultural, no repertorio comportamental de um grande contingente de pessoas. Isso se deu porque de alguma forma facilita na sobrevivência do organismo ou da cultura. A função ou relevância que esse comportamento possui vai depender de individuo para individuo dentro da sua historia de vida. "O consumo pode representar status social para uns, diferenciação para outros, inserção em determinado grupo ou ainda a manutenção de relacionamentos afetivos, dentre outros". O comportamento de consumir como forma de sentir-se feliz pode apresentar diferentes funções e é em virtude dessa funcionalidade - geralmente reforçadora - que esse comportamento é selecionado no repertorio comportamental de cada individuo.

Conforme as considerações da psicanalista os sujeitos pós-modernos não suportam o vazio e estão sempre buscando preencher esse vazio. O consumo, por sua vez, se mostra como uma via de suprimento da falta que é constitutiva do ser humano. "Desde que adquirimos a fala nós somos sujeitos faltosos, porque a fala substitui as coisas, se eu falo não preciso ficar carregando um arsenal de coisas para me comunicar, eu carrego a linguagem”. Em outras palavras, todos os sujeitos são faltosos e por dois motivos: por faltar algo que lhes complete e por cometerem erros. Essa é uma condição humana que causa angustia e o consumo surge como que para remediar tal angustia.

Finalmente, os entrevistados foram interrogados sobre quais são as possíveis implicações subjetivas que podem ser causadas nos indivíduos pelo ato de consumir em busca da felicidade e, qual o papel da psicologia nesse processo.

No que diz respeito a este aspecto o psicodrama coloca que a constituição social pósmoderna capitalista é muito individualizante e, destitui o sujeito de uma serie de coisas que o compõe colocando-o no papel de "uma parte de" e não de uma "construção em conjunto com”. Assim, forma-se uma ideia de felicidade completamente individualizante, a qual dá uma noção de que o sujeito não se constitui em lugar nenhum, apenas em si mesmo. Neste sentido, faz-se função da psicologia situar/contextualizar o sujeito no meio em que ele vive, no grupo que o compõe, para que a sua noção de felicidade não seja tão individualizante, mas que de fato, ela possa ser atribuída tanto a construção do individuo dentro de suas relações quanto que se perceba uma construção coletiva de felicidade.

Em contrapartida a comportamental defende que, a priori, o ato de consumir não representa um problema. Artigos como carro de luxo, joias, roupa de marca, etc, ocupam a Barbarói, Santa Cruz do Sul, n.46, p.<233-248>,jan./jun. 2016 
função, contemporaneamente para algumas pessoas, de um estimulo reforçador extremamente importante para a instalação ou manutenção de um comportamento. O consumo só será um problema se gerar sofrimento para o individuo. E se isso gera ou não sofrimento somente o próprio individuo pode dizer. "Se o sujeito que consome desenfreadamente diz que isso não é um problema não há porque o psicólogo intervir nisso". Por exemplo, se "um sujeito não tem dinheiro para consumir e por isso passa a sentir uma sensação de tristeza que leva ao desenvolvimento de um quadro depressivo e construção de auto-regras que passa a governar seu comportamento como o de se esquivar de situações sociais”, isso sim passa a ser um problema para a analise do comportamento. O sujeito é autônomo para fazer suas escolhas. Ainda que esse comportamento lhe cause sofrimento ele pode decidir continuar nessa vivencia assim mesmo.

Já para a psicanálise a implicação subjetiva que, consumir para ser feliz, representa é a de como o sujeito vai se constituir. "Desde o nascimento o homem é uma espécie que precisa do outro para sobreviver. O sujeito se constitui a imagem e semelhança do outro que cuida dele, é esse outro que trás os significantes e a cultura através da linguagem”. Contudo, o consumo apresenta a noção de que basta consumir para ser feliz, colocando o sujeito numa posição narcísica como se tudo fosse extensão dele mesmo, só ele se basta. A felicidade por perpassar a questão do amor, está implicada ao outro. "Todos querem ser desejados, reconhecidos e amados pelo outro". Todavia, o gozo atrelado ao objeto afasta o sujeito desse desejo primordial. Por isso, há muitos relatos hoje em dia de que as pessoas estão cada vez mais solitárias e isoladas. Assim, o papel da psicanálise é ajudar o sujeito a se constituir nesse processo, reconhecer-se como faltoso e incompleto, mas que pode conviver com o outro nesse processo de reconhecimento. "Inconsciência não é sinônimo de irresponsabilidade, assim a psicanálise tenta levar o sujeito a ser responsável por si”.

$\mathrm{Na}$ realização do grupo focal, os participantes foram indagados a respeito do que é a felicidade e como eles se posicionam com relação às formas de consumo na busca de ser feliz.

No tocante ao que se entende por felicidade, os participantes se posicionaram concordantes entre eles e deram respostas complementares entre si.

Assim, a definição resultante de suas falas é a de que felicidade é uma noção muito idealizada de um algo abstrato. Trata-se de um estado emocional que representa pequenos momentos da vida. A felicidade é resultante dos esforços de cada pessoa no intuito de conseguir prazer e o que se quer obter. E só é possível ter essa noção de felicidade porque se tem a vivencia constante de seu oposto, do contrario ninguém desejaria ser feliz. Com isso, a felicidade pode ser considerada como uma visão de mundo, uma vez que a busca por ela está Barbarói, Santa Cruz do Sul, n.46, p.<233-248>,jan./jun. 2016 
presente na maioria das atitudes dos indivíduos e ser feliz é viver essa dinâmica do trágico e da conquista.

Com relação a esse contraste felicidade/infelicidade foi dito que a vida é feita de vários momentos que podem ser feliz ou infeliz. Porem há uma predominância de que a vida seja um fracasso, por isso se busca tanto o êxito. Isso também se dá porque a nossa sociedade é de uma cultura que prega um mundo perfeito e quando as coisas dão erradas acarreta nos sintomas que mais se vê nos dias atuais: a depressão, intolerância, etc.

Ao relacionar o consumo à busca pela felicidade, os participantes declararam que a possibilidade de poder adquirir aquilo de que se gosta é importante e deixa a pessoa feliz e, obviamente, o dinheiro é um meio facilitador desse processo. O consumo é algo que não pode ser negado e dentro de um limite é ate saudável que se consuma.

Todavia, é preciso ficar atento à sedução e fetiche que o capitalismo constrói nos objetos. A questão não é simplesmente consumir e sim o valor que a pessoa passa a ter pelo que consome, como projeção social. É esse o caminho pelo qual a felicidade se apresenta através do consumo. Como se felicidade fosse sinônimo de sucesso, progresso na vida e, este por sua vez, fosse representado unicamente pelos bens materiais que o sujeito adquire.

\section{Considerações finais}

Diante do que foi exposto se percebe que o conceito de felicidade ainda não se definiu precisamente. Apesar de ser um fator de interesse da humanidade desde remotas épocas, a felicidade é entendida ou vivenciada de variadas formas, em diferentes contextos.

A partir das considerações dos teóricos estudados percebe-se que a busca pela felicidade se manifesta sempre no sentido de estabelecer certo equilíbrio do meio e do contexto envolvido, sendo a felicidade um estado que se apresenta por vezes, mas não é algo permanente na vida dos indivíduos, o que causa essa interminável busca. Entretanto é possível que os sujeitos alcancem um estado de bem-estar ou mesmo de prazer num determinado nível, suficiente para a satisfação plena.

São agravantes neste processo os novos modelos e padrões de felicidade expostos na pós-modernidade que são da ordem do imediatismo - diferentemente dos períodos anteriores à modernidade que buscavam alcançar a felicidade com o passar do tempo e com a maturidade. Ou seja, as pessoas procuram pela felicidade esperando que essa seja o resultado de todos os atos. Consequentemente, os indivíduos, agora, são acometidos por níveis mais 
elevados de ansiedade e insatisfação dentre outros, não sabendo lidar com as perdas ou frustrações.

Por meio das entrevistas com os psicólogos foi possível melhor compreender estes aspectos, uma vez que estes são possuidores de uma visão critica sobre o tema. Cada um partindo de uma abordagem psicológica especifica expos fatores que explicam como ocorre a busca da felicidade no mundo do consumo. Com a realização do grupo focal pode-se perceber como as explicações psicológicas se concretizam em vivencias humanas e quais são alguns dos seus significados para os indivíduos cotidianamente, assim como, as implicações subjetivas desse fenômeno.

Finalmente, conclui-se que a felicidade continua a ser alvo de muitas vivencias, com variadas manifestações e significações, dependendo das experiências individuais de cada sujeito. E o consumo representa uma espécie de mediação para obter-se prazer e bem-estar que são conquistas importantes para viver momentos de felicidade.

\title{
WHAT MAKES YOU HAPPY? CONSIDERATIONS ON PSYCHOLOGY IN A CONSUMMERS'SOCIETY
}

\begin{abstract}
The present work aims to identify the way happiness is seeked trough consumption as well as the subjective implications of such process through the investigation of the way psychology define happiness and how it relates to current practices of consumption. Therefore we investigated the bibliography about the subject, interviewed psychologists and made a focal group with university students. From the information we could collect, we were able to better understand the definition of happiness and the way consumption is related to it. By understanding that happiness can come from many sources we realised that consumption has been a privileged way to achieve pleasure and well-being.
\end{abstract}

Key-words: Happiness, Consumption, Psychology; Post-modernism.

\section{Referências}

ARISTÓTELES. (1990) A ética. Rio de Janeiro: Tecnoprint S.A.

BAUDRILLARD, J. (1995) A sociedade de consumo. Rio de Janeiro: Elfos,.

BAUMAN, Z. (1998) O Mal-estar da Pós-Modernidade. Rio de Janeiro: Jorge Zahar.

BERMAN, M. (1980) Tudo que é sólido desmancha no ar. A aventura da modernidade. São

Paulo: Companhia das Letras. 
CSIKSZENTMIHALYI, M. (2005) Fluir (flow): Una psicología de la felicidad. Barcelona: Kairós,.

EPICURO. (1973) Carta a Meneceu. Tradução baseada na edição de Arrighetti. Opere.

Torino. Publicação do portal veritas: www.portalveritas.blogspot.com. Acesso em: 04/05/2012.

FREUD, S. (2010) O mal-estar na civilização. São Paulo: Companhia das Letras.

GIANNETTI, E. (2002) Felicidade: diálogos sobre o bem-estar na civilização. São Paulo:

Companhia das Letras.

HALL, S. (2000) A identidade cultural na pós-modernidade. Rio de Janeiro: DP\&A.

LIPOVETSKY, G. (2007) A felicidade paradoxal: ensaio sobre a sociedade de

hiperconsumo. São Paulo: Companhia das Letras.

MICHALISZYN, M. S. \& TOMASINI, R. (2011) Pesquisa: orientações e normas para elaboração de projetos, monografias e artigos científicos. Petrópolis, RJ: Vozes.

ROUANET, S. P. (1998) Mal-estar na modernidade. São Paulo: Companhia das Letras.

SANTOS, J. F. (2000) O que é pós-moderno. São Paulo: Brasiliense, 2000.

Data de recebimento: $26 / 07 / 14$

Data de aceite: $27 / 03 / 17$

\section{Sobre os autores:}

Marcio Acselrad é Psicólogo formado pela Universidade Federal do Rio de Janeiro. Mestre e Doutor em Comunicação pela UFRJ. Professor Doutor de Psicologia Social,de Teoria da Comunicação e de Estética da Unifor: Universidade de Fortaleza. Professor de Psicologia Jurídica do Centro Universitário Unichristus. Coordenador do Cineclube Unifor e do Cineclube Gazeta-Unichristus. Pesquisador do LABGRAÇA: Laboratório de Estudos do Humor e do Riso e do LAEPCUS: Laboratório de Estudos sobre Psicanálise, Cultura e Subjetividade do Programa de Pós-Graduação em Psicologia da Unifor. Colaborador do programa de pós-graduação em Comunicação da UFC: Universidade Federal do Ceará. Endereço Eletrônico: macselrad@gmail.com

Josefa Crysleide Rodrigues Lopes é Psicóloga graduada pela Universidade de Fortaleza UNIFOR. Bolsista de Iniciação Científica da FUNCAP. Endereço Eletrônico: crysleiderodrigues@ hotmail.com 